\title{
Severe neurotoxic envenoming by the Malayan krait Bungarus candidus (Linnaeus): response to antivenom and anticholinesterase
}

\author{
DAVID A WARRELL, SORNCHAI LOOAREESUWAN, NICHOLAS J WHITE, \\ R DAVID G THEAKSTON, M J WARRELL, WYPHOT KOSAKARN, H ALISTAIR REID
}

\begin{abstract}
Five patients were bitten by the Malayan krait Bungarus candidus (Linnaeus) in eastern Thailand or north western Malaya. Two patients were not envenomed but the other three developed generalised paralysis which progressed to respiratory paralysis in two cases, one of which ended fatally. One patient showed parasympathetic abnormalities. Anticholinesterase produced a dramatic improvement in one patient. Another patient probably benefited from paraspecific antivenom.

The efficacy of antivenoms and adjuvants such as anticholinesterases in patients with neurotoxic envenoming requires further study.
\end{abstract}

\section{Introduction}

Venoms of kraits (genus Bungarus) have attracted much interest among neuropharmacologists since the discovery that bungarotoxins interfere with transmission at the neuromuscular junction. ${ }^{1}$ Kraits are common in many Asian countries yet the reported incidence of bites is low. In the few published reports mortality has been high $-77 \%$ in 35 cases of $B$ caeruleus bite in India, ${ }^{2}$ $23 \%$ in 925 cases of $B$ multicinctus bite in Taiwan. ${ }^{3}$ The Malayan krait $B$ candidus is common in south east Asia, ranging from Thailand to China and south to Indonesia, ${ }^{4}$ but clinical reports of proved bites by $B$ candidus have not been published. (Older published work is confusing because the common Indian krait $B$ caeruleus is sometimes incorrectly referred to as $B$ candidus. $\left.{ }^{4}\right)$ We report the cases of five patients bitten by $B$ candidus and their response to antivenom and anticholinesterase drugs.

\section{Case histories}

CASE 1

A 13 year old Thai boy was bitten on the thigh at 3 am while sleeping on the floor of a hut in Chantaburi region, eastern Thailand. The snake was an $1100 \mathrm{~mm}$ long $B$ candidus. (The specimen is deposited in the British Museum (Natural History), London, accession No 1982.457.) Within half an hour there was slight swelling, redness, and numbness, but no pain, at the site of the bite and abdominal discomfort. At the health station three hours after the bite

Faculty of Tropical Medicine, Mahidol University, Bangkok 10400, Thailand

DAVID A WARRELL, DM, FRCP, consultant

SORNCHAI LOOAREESUWAN, MD, DTM\&H, staff member

NICHOLAS J WHITE, BSC, MRCP, Wellcome lecturer

M J WARRELL, MRCP, MRCPATH, consultant

WHO Collaborative Centre for the Control of Antivenoms, Liverpool School of Tropical Medicine, Liverpool L3 5QA

R DAVID G THEAKSTON, PHD, senior lecturer

H ALISTAIR REID, MD, FRCPED, director

Pra Pokklao Hospital, Chantaburi, Thailand

WYPHOT KOSAKARN, MD, surgeon he was breathless and unable to open his mouth or swallow. Doses of $\frac{\vec{\sigma}}{2}$ $20 \mathrm{ml}$ non-specific antivenom, $8 \mathrm{mg}$ dexamethasone, and $0.5 \mathrm{mg}$ 응 atropine were given intravenously. At four hours he could not breathe and was intubated and ventilated manually.

On admission to Pra Pokklao Hospital, Chantaburi, seven and a half hours after the bite the patient was fully conscious but almost $\vec{\omega}$ completely paralysed and had bilateral ptosis. He replied to questionso by flexing fingers and toes. When manual ventilation was stoppedo briefly he became distressed, sweaty, and cyanosed. The site of the bite was slightly tender but not swollen and showed the imprint of fangs and teeth. The pulse was $120 / \mathrm{min}$ and regular and blood pressureos $140 / 70 \mathrm{~mm} \mathrm{Hg}$. The abdomen was moderately tender. There was flaccid tetraparesis with total bilateral external ophthalmoplegia, pronounced ptosis, inability to open the mouth, protrude the tongue or swallow, and no gag reflex (table). Tendon and abdominal reflexes

Summary of clinical findings in three patients envenomed by Bungarus candiduso

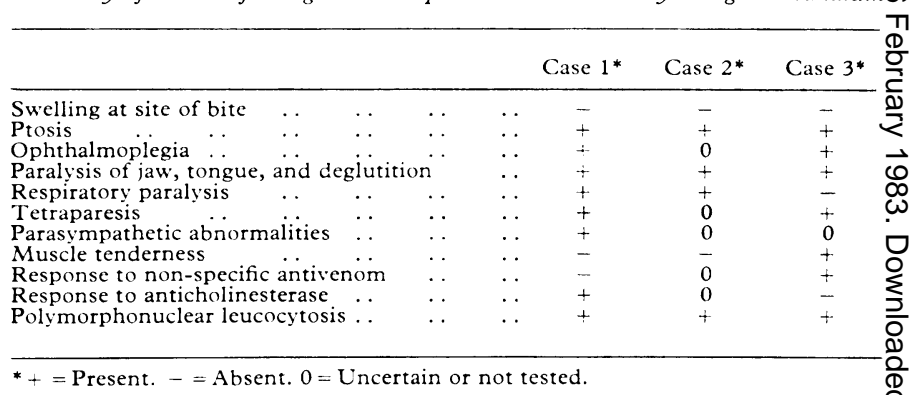

were absent. Manual ventilation, performed by relatives and nurses, was required for a total of 49 hours. On the third day after the bite the eyes were divergent but capable of slight movement in the horizontato plane and downward but not upward. Ptosis hooded two thirds of the pupil.

On admission the pupils had been fixed and dilated but the patient could see. Pupillary constriction induced by pilocarpine eye drops waso tested over a range of concentrations from $0.04 \%$ to $4.0 \%$ and was considerably reduced on day 3 compared with one month later. While the patient was paralysed the pulse rate was continuously above $120 / 3$ min. There was sweating and increase in pulse rate in response to difficulties with the airway. There was no reduction in heart rate or blood pressure with changes in position or massage of the carotid sinus. Normal responses were elicited when the patient was reinvesti- $\rightarrow$ gated one month after the bite. Heart rate rose from 122 to 133 음. beats $/ \mathrm{min}$ after intravenous atropine $0.6 \mathrm{mg}$. Lacrimation and salivation appeared to be normal and bowel sounds were audible.

Laboratory investigations-On admission there was a neutrophil leucocytosis $\left(90^{\circ}\right.$ of $22.4 \times 10^{9}$ cells/1), which subsided within the next four days. Results of biochemical and haematological investiga tions, including tests of blood coagulation, remained normal through- $\frac{-}{\Phi}$ out. Using an enzyme linked immunosorbent assay ${ }^{5} B$ candidus venomes antigen equivalent to $100 \mu \mathrm{g}$ venom/1 was detected in the serum $15^{\circ}$ hours after the bite, but not earlier or subsequently. Antigen was not detected in urine. Specific $B$ candidus venom antibody was found in $\overrightarrow{\mathbb{D}}$ serum five weeks after the bite. The patient could breathe unassisted $\stackrel{9}{T}$ by the third day, and therafter a gradual increase in muscle power was evident, distal groups improving more rapidly than proximal ones $\sigma$ He was considered completely normal on the 14th day.

Treatment-Doses of $50 \mathrm{ml}$ and $100 \mathrm{ml}$ of Thai Red Cross Societyo monospecific banded krait ( $B$ fasciatus) antivenom were infused $12 \leq$ and 20 hours after the bite without response. On the third day $10 \mathrm{mg}$. edrophonium was given intravenously after $0.6 \mathrm{mg}$ atropine. There? 
was an immediate improvement in ptosis, eye movements, and ability to open the mouth and protrude the tongue. The mean time before the lid dropped to hood more than half of the pupil during attempted upward gaze was prolonged from 28 to 70 seconds. The range of eye movements was increased bilaterally by $35^{\circ}$ in the horizontal plane and $30^{\circ}$ in the vertical plane. Contraction of intercostal and accessory muscles of respiration could be seen and felt for the first time and the sustained maximum expiratory pressure increased from 0.5 to 1.6 $\mathrm{kPa}$ ( 4 to $12 \mathrm{~mm} \mathrm{Hg}$ ). The pressure generated by gripping and by plantar flexing against a partially inflated sphygmomanometer cuff increased by $25 \%$ and $20 \%$ respectively. These improvements had disappeared 30 minutes later but were restored by a continuous infusion of neostigmine $(0.5 \mathrm{mg} / \mathrm{h})$ given with atropine $(0.15 \mathrm{mg} / \mathrm{h})$. Deterioration was noted after stopping the infusion six hours later, with improvement on restarting and continuing for 24 hours.

CASE 2

A 44 year old woman who slept on the floor of a rice mill near Chantaburi was bitten on the big toe at 3 am by what she thought was a skink (Mabuya multifasciata). The only immediate symptoms were slight local pain and bleeding. She awoke again 30 minutes later breathless and with numbness of the bitten toe and foot. In hospital 35 minutes later she complained of difficulty with breathing and inability to open her mouth.

Examination (table) showed ptosis, tachycardia, and a normal blood pressure. Two hours after the bite she complained of blurred vision and generalised numbness in addition to increasing breathlessness. Two hours later she suffered a respiratory and cardiac arrest from which she was resuscitated but required artificial ventilation. When we first saw her, 14 hours after the bite, there was a single puncture mark on the toe. Anoxic brain death was suspected and she died three hours later.

Laboratory investigations showed a polymorph leucocytosis $(93 \%$ of $13.3 \times 10^{9}$ cells $/ 1$ ). B candidus venom antigen (equivalent to $200 \mu \mathrm{g}$ venom $/ 1$ ) was detected in tissue fluid aspirated from the bite site.

\section{CASE 3}

A 39 year old Chinese man was bitten on the ankle at $330 \mathrm{pm}$ while farming in Kedah, Malaya. The snake was a $520 \mathrm{~mm}$ long $B$ candidus. He walked home, and two hours later headache and giddiness were soon followed by difficulty in keeping his eyes open and swallowing. Pains in the trunk and limbs started four and a half hours after the bite. Movement aggravated the pains, which progressively increased precluding sleep. He was admitted to Penang General Hospital 19 hours after the bite. On examination fang marks were evident but there was no swelling, discoloration, or tenderness at the site of the bite or of regional lymph nodes. He was conscious and responded by grunts or slight hand movement. Pulse was $90 / \mathrm{min}$, respiration $25 / \mathrm{min}$, and blood pressure $130 / 70 \mathrm{~mm} \mathrm{Hg}$. There was bilateral ptosis, total external ophthalmoplegia, and paralysis of facial muscles (table). Maximal jaw opening was $1 \mathrm{~cm}$ between teeth margins. He could not protrude his tongue or swallow. Pupillary responses were normal. There was generalised paresis. All muscles were tender, and passive movements were very painful. Fasciculation were evident in the legs. Tendon and plantar reflexes and sensation appeared normal.

Treatment-Intravenous infusion of $100 \mathrm{ml}$ Haffkine polyspecific ( $B$ caeruleus, Echis carinatus, Vipera russelli, Naja naja) antivenom was started 20 hours after the bite. Within five minutes an anaphylactoid reaction developed but responded promptly to adrenaline, after which the antivenom infusion was completed in 30 minutes. One hour after starting antivenom the patient indicated that he felt much better, and four hours later there was clear objective improvement. Eye movements had returned to $75 \%$ of normal, ptosis to $25 \%$ normal, maximal jaw opening was $3 \mathrm{~cm}$ between teeth margins, and he could protrude his tongue $2 \mathrm{~cm}$ beyond teeth margins. Hand grips were stronger and pains on muscle movement seemed less severe. He could lift his head and heels off the bed for a few seconds. At seven hours after antivenom he could swallow; 22 hours after antivenom (42 hours after the bite) eye movements were normal but ptosis was unchanged, jaw opening was $2 \cdot 2 \mathrm{~cm}$, and tongue protrusion was also $2 \cdot 2 \mathrm{~cm}$. Head raising was $50 \%$ of normal and he was just able to turn on to his side. Forty eight hours after the bite $1 \mathrm{mg}$ neostigmine was injected subcutaneously after $0.6 \mathrm{mg}$ atropine. He "felt better" but there was no objective improvement in muscle power during the subsequent three hours. Three days after the bite he could walk though was still unable to sit up in bed unaided. Pains on muscle movement were minimal. Jaw opening $(5 \mathrm{~cm})$, tongue protrusion ( 3 $\mathrm{cm}$ ), speech, and swallowing were normal. Thereafter limb and trunk power improved to complete recovery six days after the bite.

Investigations-On admission the white blood cell count was $17 \cdot 4 \times 10^{9} / 1(90 \%$ neutrophils) and became normal three days later. Other haematological indices and clot quality remained normal. Results of urine analysis were normal. Serum aspartate and alanine transaminase activities were initially normal, but alanine activity rose to a peak of $128 \times 10^{3} \mathrm{U} / 1$ seven days after the bite, falling to normal (below $45 \times 10^{3} \mathrm{U} / 1$ ) in four days. Aspartate transaminase activities remained normal (below $42 \times 10^{3} \mathrm{U} / \mathrm{l}$ ) except for a value of $55 \times 10^{3}$ $\mathrm{U} / 1$ five days after the bite. Other biochemical values were normal.

\section{CASES 4 AND 5}

An 11 year old girl was bitten at 4 am by a $1400 \mathrm{~mm}$ long $B$ candidus (British Museum (Natural History) accession No 1982.458) near Chantaburi, and a 47 year old Chinese man was also bitten at 4 am by an $1100 \mathrm{~mm}$ specimen of the same species in Kedah. Neither patient developed evidence of envenoming.

\section{Discussion}

This series shows that $B$ candidus can cause severe neurotoxic envenoming in man. Like the Indian krait $B$ caeruleus $^{2}$ and the African spitting cobras, ${ }^{6}{ }^{7} \mathrm{~B}$ candidus usually bites at night while the victims are asleep at home. The incidence of $B$ candidus bites has probably been underestimated, and immunodiagnostic methods (see case 2) may confirm a higher incidence of envenoming by this species. Two patients (cases 4 and 5) were bitten by large snakes yet showed no evidence of poisoning, re-emphasising that highly venomous species may bite without injecting venom.

The preparalytic phase may be as long as 12 hours after krait bites, ${ }^{2} 8$ although in our cases paresis started between 75 minutes and three hours after the bite. Local effects were negligible. In cases 1,2 , and 3 there was virtually complete neuromuscular paralysis, proceeding in cases 1 and 2 to respiratory failure. The survival with complete recovery in case 1 illustrates the value of prolonged assisted ventilation, ${ }^{9} 10$ particularly when effective antivenom is not available. The abnormalities in the parasympathetic nervous system in case 1 suggest that krait venoms have cholinergic blocking activity ${ }^{8}$ apart from familiar effects on neuromuscular transmission. In case 3 the generalised pains on muscle movement resembled those in patients envenomed by sea snakes ${ }^{11}$ and Australian land snakes. ${ }^{12}$ Generalised rhabdomyolysis was excluded, however, by normal serum creatinine and aspartate transaminase activities and the absence of myoglobinuria.

In case 1 banded krait ( $B$ fasciatus) antivenom did not benefit the patient, whereas in case 3 there was significant improvement four hours after Haffkine polyspecific antivenom, although the possibility of spontaneous improvement cannot be excluded. We have tested the ability of four antivenoms to protect mice from the lethal effects of $B$ candidus venom. Thai $B$ fasciatus and Taiwan $B$ multicinctus antivenoms were ineffective. Haffkine antivenom was effective $\left(\mathrm{ED}_{50}\right.$ against $5 \mathrm{LD}_{50}$ venom intravenously, $28 \mu \mathrm{l} /$ mouse) and Australian tiger snake antivenom was even more effective $\left(\mathrm{ED}_{50} 14 \mu \mathrm{l} /\right.$ mouse).

In case 1 edrophonium produced a dramatic improvement, suggesting that neither the parasympathetic cholinergic nerve terminals nor the motor end plates were completely blocked. Experimentally the neuromuscular blocking activity of snake venom fractions are often reversible by anticholinesterases, ${ }^{1}$ whereas the activity of whole venoms is affected much less if at all. ${ }^{13}$ Clinical impressions have been both favourable ${ }^{1415}$ and (as in case 3) unfavourable. ${ }^{81011} \mathrm{We}$ conclude that further critical clinical studies, including objective measurements, are needed both of antivenoms and of adjuvant treatment such as anticholinesterases in neurotoxic envenoming. 
We thank Miss Eunice Berry and Miss Jean Taylor for secretarial help and the Wellcome Trust and Medical Research Council for financial support. Studies in Thailand were part of the WellcomeMahidol University-Oxford, Tropical Medicine Research Programme.

Requests for reprints should be addressed to: Dr D A Warrell, Faculty of Tropical Medicine, Mahidol University, 420/6 Rajvithi Road, Bangkok 10400, Thailand.

\section{References}

' Chang CC. The action of snake venoms on nerve and muscle. In: Lee C-Y, ed. Snake venoms. Berlin: Springer-Verlag, 1979:309-76.

'2 Ahuja ML, Singh G. Snake bite in India. Indian 7 Med Res 1954;42: 661-86.

${ }^{3}$ Kuo T-P, Wu C-S. Clinico-pathological studies on snakebites in Taiwan The Snake 1972;4:1-22.

4 Smith MA. Fauna of British India Ceylon and Burma including the whole of the Indo-Chinese sub-region. Reptilia and Amphibia. Vol III. Serpentes. London: Taylor and Francis, 1943.

${ }^{5}$ Theakston RDG, Lloyd-Jones MJ, Reid HA. Micro-elisa for detecting and assaying venom and venom antibody. Lancet 1977;ii:639-41.

6 Warrell DA, Greenwood BM, Davidson NMcD, Ormerod LD, Prentice
CRM. Necrosis, haemorrhage and complement depletion following bites by the spitting cobra (Naja nigricollis). $Q \mathcal{F}$ Med $1976 ; 45: 1-22$. (D

7 Tilbury CR. Observations on the Mozambique spitting cobra (Najo mossambica mossambica). S Afr Med F 1982;61:308-13.

${ }^{8}$ Sethi PK, Rastogi JK. Neurological aspects of ophitoxemia (Indian krait - a clinico-electromyographic study. Indian $\mathcal{F}$ Med Res $1981 ; 73: 269-76 \bar{J}$

${ }^{9}$ Richards V. Dr Fayrer's treatment of snake-bite by artificial respirationg Indian Medical Gazette 1873;8:118-20.

${ }^{10}$ Campbell $\mathrm{CH}$. Venomous snake bite in Papua and its treatment with tracheostomy, artificial respiration and antivenene. Trans $R$ Soc Trop Med Hyg 1964;58:263-73.

11 Reid HA. Diagnosis, prognosis and treatment of sea-snake bite. Lance 1961 ;ii :399-402.

12 Hood VL, Johnson JR. Acute renal failure with myoglobinuria after tige? snake bite. Med $\mathcal{F}$ Aust 1975;ii:638-41.

${ }^{13}$ Chang CC. Studies on the mechanism of curare-like action of Bungarua multicinctus venom. I. Effect on the phrenic nerve-diaphragm prepara? tion of the rat. Fournal of the Formosan Medical Association 1960;59@ 315-23.

14 Banerjee RN, Sahni AL, Chacko KA. Neostigmine in the treatment of Elapidae bites. F Assoc Physicians India 1972;20:503-9.

${ }^{15}$ Ramakrishnan MR, Sankaran K, Gupta GD, Chandrasekar S. External. ophthalmoplegia in Elapidae bites and its response to neostigmine $\vec{\omega}$ Neurology India 1975;23:109-10.

(Accepted 24 December 1982)

\title{
Intramuscular on demand analgesia: double blind controlled trial of pethidine, buprenorphine, morphine, and meptazinol
}

\author{
M HARMER, P J SLATTERY, M ROSEN, M D VICKERS
}

\begin{abstract}
An on demand intramuscular analgesic system using the Cardiff Palliator was tested. Forty consenting patients were studied after cholecystectomy in a double blind trial using increments of buprenorphine (0.15 $\mathrm{mg})$, meptazinol $(50 \mathrm{mg})$, morphine $(5 \mathrm{mg})$, and pethidine $(50 \mathrm{mg})$. Most patients attained good levels of pain relief (mean analogue pain score 36.5 ), comparable to intravenous on demand analgesia. There were no technical complications. Significant differences were found between drugs in dizziness (pethidine produced the worst score) but not with other side effects. Buprenorphine produced longer lasting analgesia than meptazinol or pethidine and also gave the lowest pain scores. Patterns of analgesic consumption were the same as with intravenous on demand systems, but larger amounts of drug were generally used. Relative analgesic potencies derived from drug consumption rates were also consistent with those from intravenous on demand studies.

An on demand intramuscular analgesic system offers a simple but effective means of relieving severe postoperative pain.
\end{abstract}

\section{Introduction}

Routine intermittent intramuscular injections of analgesic administered by nurses do not give good postoperative analgesia $\$$ and many other methods of administration have been claimed to give better results. ${ }^{2-6}$ Studies on any novel system for dispensing analgesics are apt to yield better results than existing practice by increasing the attention paid to individual patients. The value. of any innovation will, however, also depend on implementatios and practicality for routine use.

A system combining the simplicity (and acceptability to nursing staff) of intramuscular injections together with the versatility (and intuitive appeal to patients) of an on demanis system would seem to have practical advantages.

An initial pilot study showed that repeated injections througd an indwelling intramuscular cannula produced little or n\& discomfort so long as the volume and rate of injection wer? limited. This study was performed to determine whether a intramuscular on demand system would give good postoperative pain relief without introducing further problems. As the effectiveness of intramuscular analgesics may be influenced bow physicochemical factors affecting rate of absorption, fou里 different drugs (buprenorphine, meptazinol, morphine, and pethidine) were studied. Morphine and pethidine have been̄ used in most methods of pain relief so far described; buprenor? phine and meptazinol have been studied in intravenous op demand systems. ${ }^{78}$

\section{Methods}

Forty patients undergoing uncomplicated elective cholecystectom were studied; they were aged between 18 and 70 years, and none of the women was pregnant. The trial was conducted double blin patients being allocated at random to receive one of the analgesics for 